Kohl: a Journal for Body and Gender Research

Vol. 6, No. 2 (Fall 2020)

\title{
Inhabiting Atypical Bodies and Minds
}

\author{
Aude Nasr
}


Oppressions intersect in as many ways as there are people, and though life experiences can sound similar, what characterizes us as humans is also the way we create our own, distinct worlds out of these experiences - and how we inhabit non-conforming bodies and minds.

While illustrating these stories, what was important to me was to tune into the emotions emerging from each one of their characters and protagonists, along with their personal and intimate experience of living at the intersection of disability/sickness, and other aspects of their lives that are subject to marginalization.

I believe we will always need to be creating new imaginaries for ourselves, and for our stories - whether we use words, sounds, or images - especially if people like us have been little or badly represented. I hope these illustrations contribute to underlining the imaginaries and beauty of their narrators. Thank you to Ghiwa and the whole team for giving me the change to illustrate for them.

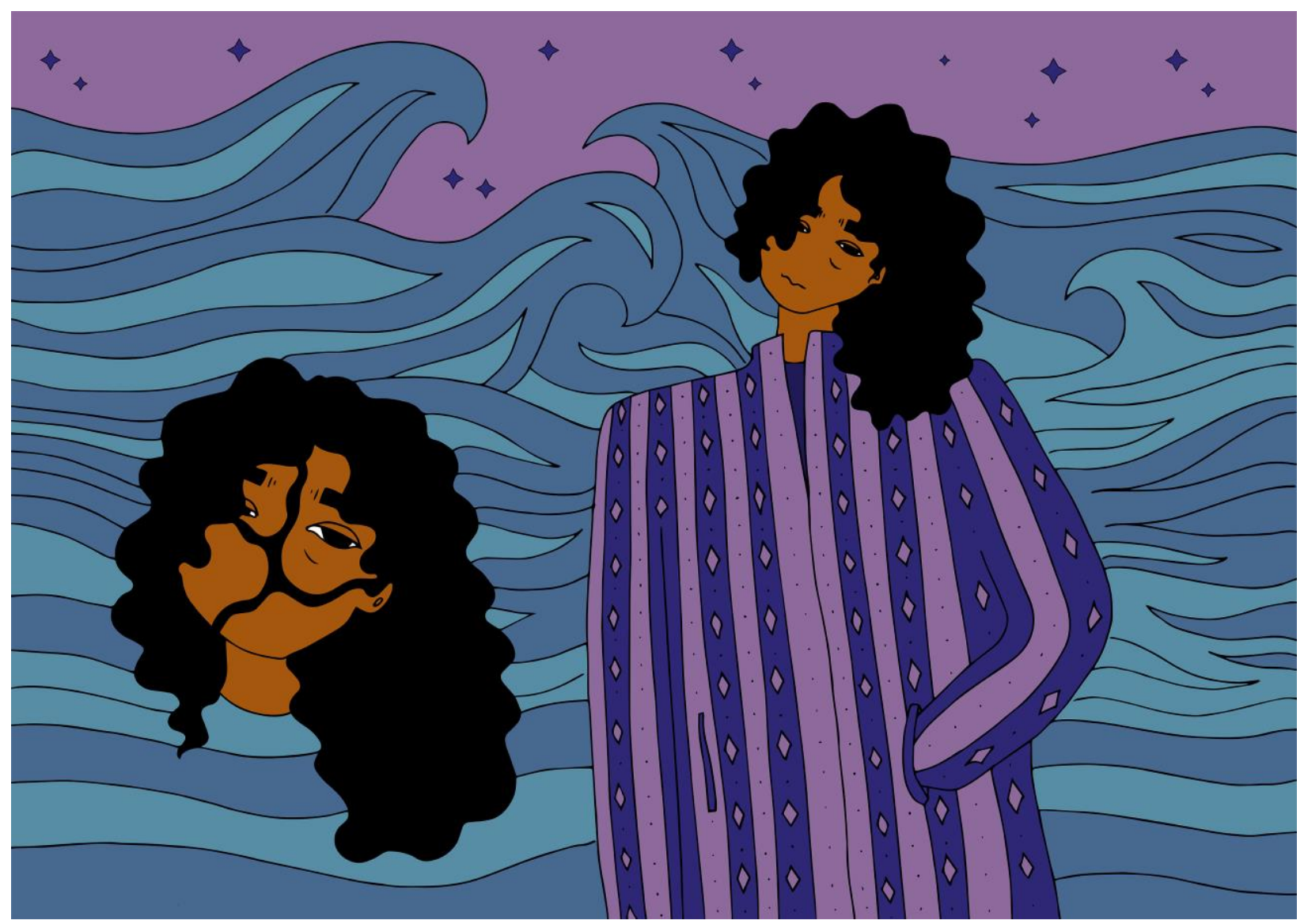


Kohl 6.2

172

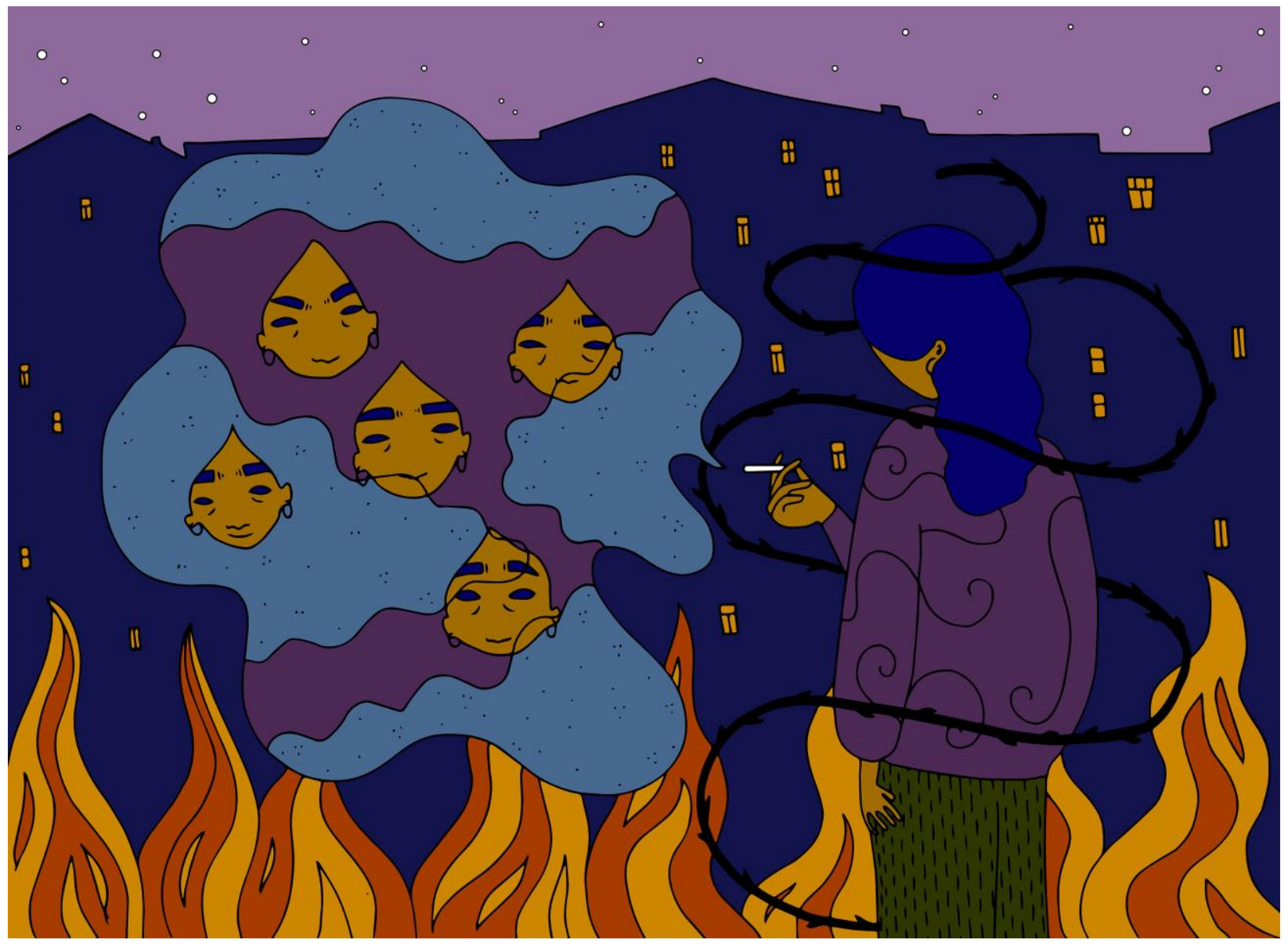

The Other Her 


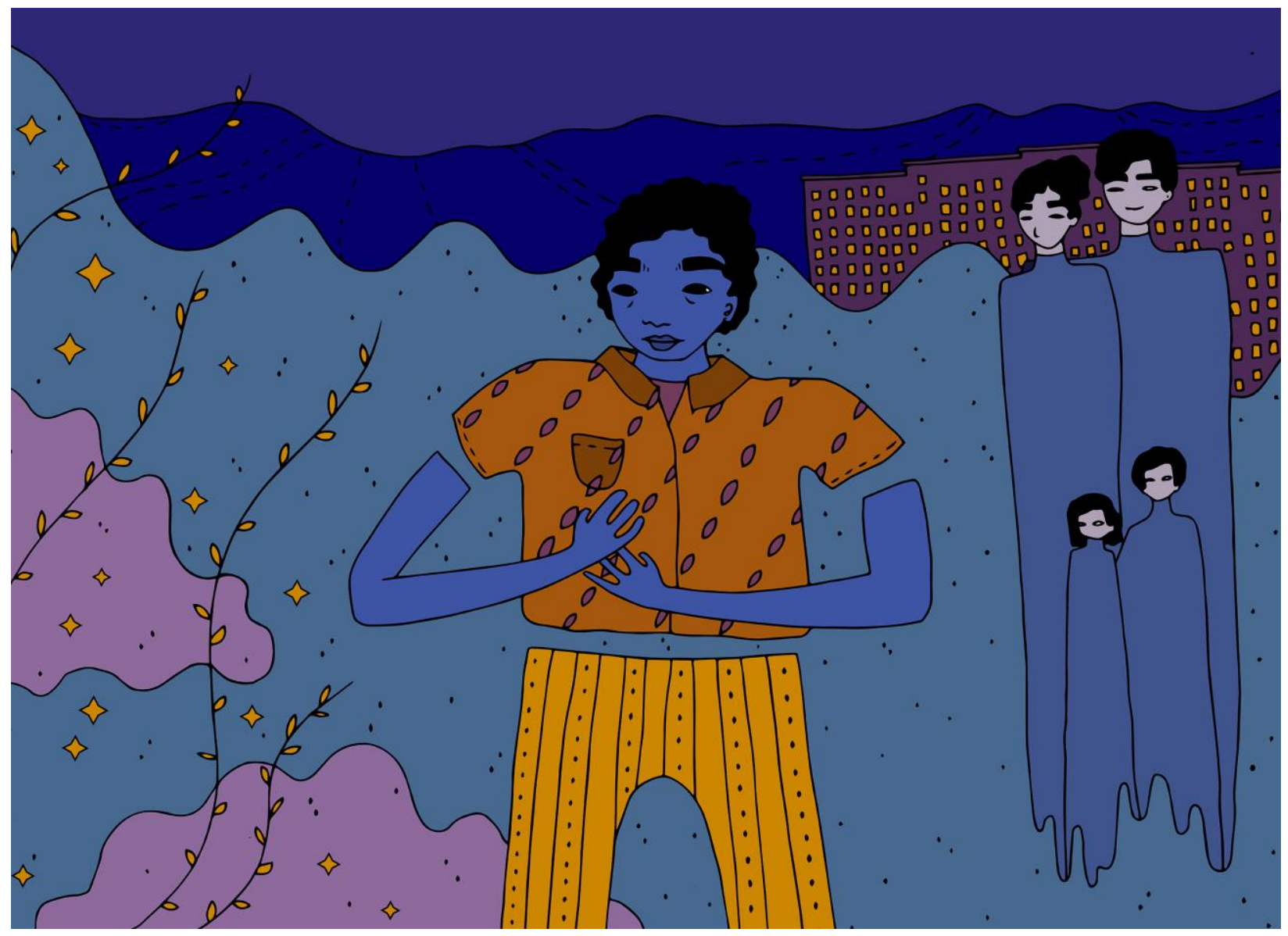

"Nobody is going to want her like this" 


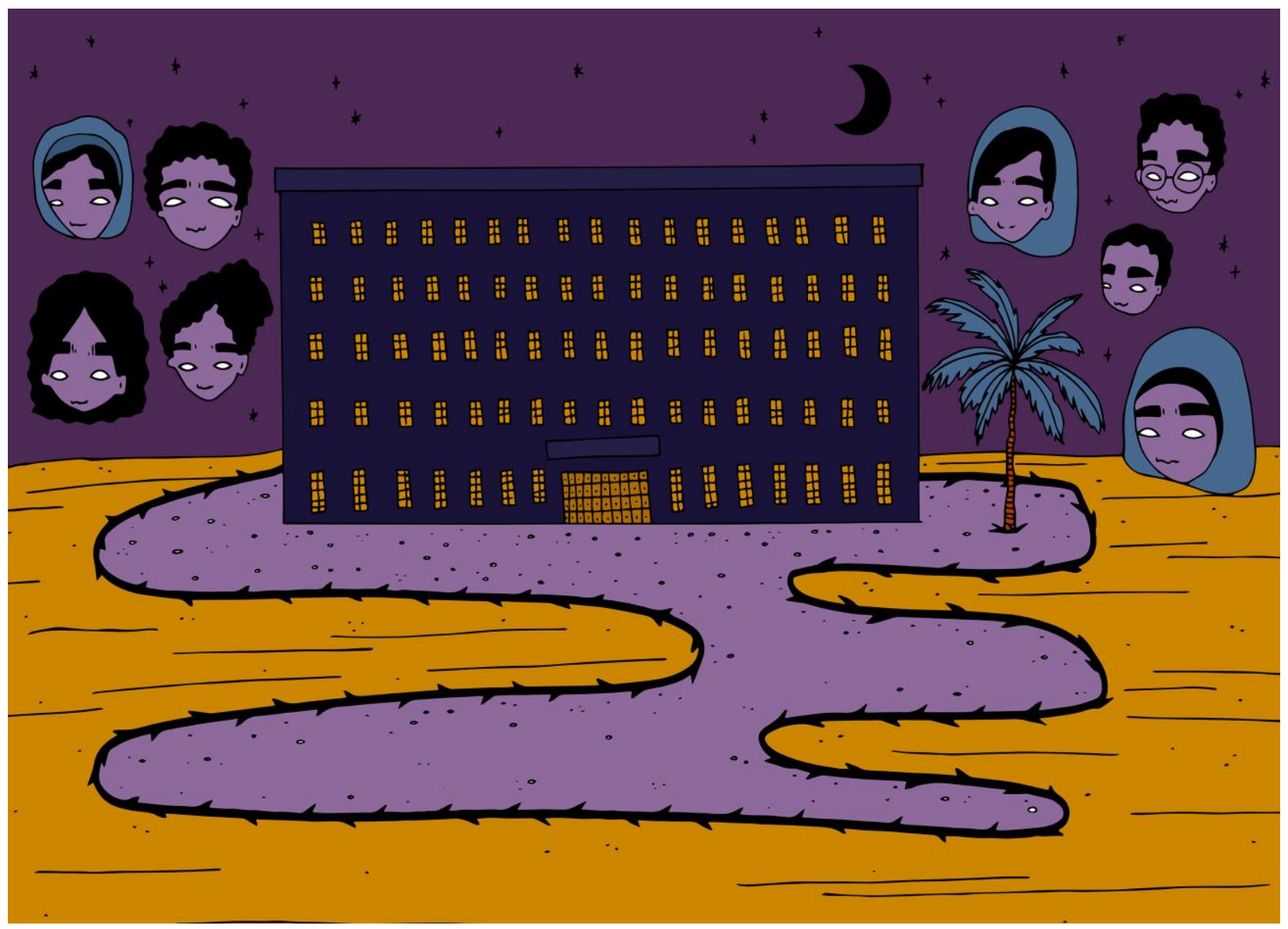

Carceral Responses to Neuro-divergence 